\title{
Rasgos culturales y desarrollo de las PYMES
}

José Luis Rocha

Resumen.- El hecho de que la fluidez de la información, la confianza y la gobernabilidad sean difícilmente calculables y que no puedan por tanto ser incluidas entre las variables de los modelos econométricos, les ha marginado de los análisis económicos. Según el economista italiano Andrea Saba, el excluir esos rasgos de los estudios económicos es un error gravísimo que difunde una forma de falsa cultura economicista que pretende explicar el complejo fenómeno del desarrollo con base únicamente en variables de naturaleza económica que permitan un tratamiento modelístico (Saba, 1997:31-32). Este artículo se ocupa de otro tipo de variables, como son los rasgos culturales, para reseñar de manera sucinta su impacto sobre el desarrollo de las PYMES. Aborda algunos rasgos culturales que han sido tenidos como adversos. Pero la tesis esencial es que los rasgos culturales, calificados como adversos o no, o en ocasiones tenidos como elementos folklóricos improductivos, pueden ser transformados en recursos económicos mediante innovaciones empresariales.

\section{Introducción}

Este artículo fue concebido teniendo en mente a los promotores de pequeñas y medianas empresas. Ya sea por una profunda convicción interna (de origen emocional o bien de naturaleza científica, es decir, fundada en una demostración del potencial y peso de las PYMES en la economía nacional) o porque hay que creer en lo que nos da de comer, el número de promotores-adeptos de la fe en las PYMES en Nicaragua se ha multiplicado con una celeridad que fácilmente supera el vigor de las PYMES. Los más maliciosos aseguran que por cada artesano de Masaya existen al menos 3 promotores. No obstante, su labor se realiza en medio de un mar de indefiniciones que tienen un costo para la cooperación internacional, para el desarrollo de Nicaragua en general y para el de los pequeños y medianos empresarios, sector meta de los programas de promoción.
En parte, esas indefiniciones se manifiestan para tocar la raíz, en la acepción misma del término "PYMES". El paradigma del desarrollo basado en las PYMES tiene la maravillosa cualidad de que permite a cada quien agrupar bajo ese término el género de empresa que le apetezca. Un estudio de Alicia Sáenz describe esta situación: "Los conceptos $y$ definiciones de las PYMES en Nicaragua, no están aún consolidados, dado que el interés sobre el sector es relativamente nuevo; esto hace que el mismo carezca de sistema para la elaboración de estadísticas propias que permitan darle continuidad a su comportamiento y base estadística a su definición." (Sáenz, 1996:3)

Se han diseñado diversas tipologías de PYMES conforme rangos de ingresos, número de trabajadores y volumen de producción. Pero se continúa hablando y escribiendo sobre las PYMES sin especificar la gama de empresas que se hospedan en ese concepto, lo que ha 
dado lugar a más de un equívoco. Destaquemos uno de ellos; por un lado, algunos mencionan que las PYMES en América Latina actualmente conforman entre el 95 y el $99 \%$ de las empresas legalmente establecidas, ofrecen del 60 al $80 \%$ del empleo y aportan del 30 al $50 \%$ del PIB (La Prensa, 19 nov. 1997:2B). Evidentemente aquí se ocupan, como en la mayoría de los estudios, de las empresas formalmente constituidas que representan sólo una fracción muy reducida del universo de las PYMES en su sentido más amplio. Por otra parte, se sostiene que en Nicaragua existen entre 450,000 y 500,000 PYMES de las cuales dependen aproximadamente 3 millones de personas (Geyer-González-Queck-Schor, 1997:4). En este grupo, en cambio, es obvio que se ha incluido toda la economía subterránea que incluye empresas no legalizadas. Los datos sobre la generación de empleo incluyen el racimo más heterogéneo de PYMES: desde comedores y pulperías hasta pequeñas imprentas, desde el comercio en el Huembes y el Oriental hasta las queserías de Matiguás. Pero cuando se gestionan los programas de apoyo, generalmente se piensa ante todo en artesanos, ebanistas, zapateros, costureros y agricultores. Un número muy reducido de ramas productivas acaparan el apoyo. Dado cierto grado de rigidez en estos programas, este sesgo no deja de tener sus consecuencias sobre una visión $y$ actitud auténticamente empresarial, como explicaré más adelante. Optando por la disminución del desempleo como prioridad, desde ahora aclaro que aquí me referiré a las PYMES en sentido lato. Un intento de profundizar sobre la problemática de las indefiniciones en torno a las PYMES, nos lanza hacia el terreno de la promoción y sus agentes. En muchos casos, la promoción está concebida de tal suerte que los promotores catan poco del ambiente en que promueven y pretenden promover a control remoto, apoltronados en sus sillones y deslizándose "cada muerte de obispo" hacia las empresas que asisten. Nada más lejano a los patrones de monitoreo adoptados por empresas privadas de éxito. Por ejemplo, es muy citado el caso de Ray Kroc, el fundador de McDonalds, que visitaba varios de sus establecimientos a la semana a fin de constatar la calidad de los productos, la eficiencia del servicio y la esmerada atención a la clientela. Con justa razón Norman Schofield se ha preguntado "cuál es la cantidad mínima que un agente debe conocer en un medio determinado sobre las creencias y necesidades de otros agentes para poder formarse ideas coherentes sobre su conducta y para que ese conocimiento sea comunicable a los demás." (North, 1993:28). Sólo un contacto permanente puede proporcionar nociones con relación a un factor clave del que queremos ocuparnos aquí: el trasfondo cultural. Su ignorancia puede conducir a errores y al menos podemos asegurar que ha desperdiciado jugosas oportunidades.

Aquí únicamente pretendo lanzar algunas pistas basándome en un enfoque cultural, suponiendo que las evoluciones técnicas, financieras y organizativas se desarrollan paralelamente a evoluciones culturales y que su advenimiento se ve favorecido o retardado por rasgos de la idiosincrasia. Señalaré algunos de los rasgos culturales que son adversos o propicios al desarrollo de las PYMES. Esta óptica no es nueva; tuvo su más conspicuo representante en Max Weber, 
cuya obra "La ética protestante y el espíritu del capitalismo" hizo época y mostró cómo ciertos elementos en la cosmovisión calvinista fueron claves para el desarrollo del capitalismo.

Según Weber, si bien la doctrina calvinista de la predestinación, introducía un elemento pesimista porque postulaba que el número de los elegidos ya estaba determinado por Dios desde el inicio de la creación y ningún proceder sería capaz de modificarlo, esto quedaba subsanado por el deber del creyente de considerarse elegido y de que todo su trabajo social estuviera orientado, no a gestionar su salvación, sino únicamente in maiorem Dei gloriam; de ahí una serie de actuaciones que no son motivadas tampoco por el amor al prójimo, sino por el objetivo de dar estructura racional al cosmos que nos rodea, lo que genera ese trabajo al servicio de la impersonal utilidad social que produjo la dedicación al trabajo, la abstinencia, la acumulación de capital, las sucesivas inversiones y los hombres de negocios del período heroico del capitalismo (Weber, 1975:131-138).

Así fue como la ética calvinista produjo, no el afán de lucro que Weber consideraba común a diversas culturas y épocas, sino la orientación racional de todos los recursos y esfuerzos hacia la maximización de las ganancias, la acumulación a base de austeridad y la reinversión. La maquinaria ideológica calvinista elaboró una doctrina que dio soporte a un comportamiento saludable al capitalismo. El contexto cultural fue caldo propicio para el cultivo de ciertas "virtudes" económicas.

Pero Weber tuvo predecesores no menos ilustres y de aguda intuición. CharlesLouis de Secondat, Barón de la Brede y de Montesquieu (1689-1755), aristócrata y abogado francés, presidente del
Parlamento de Burdeos y célebre por su erudita obra "Del Espíritu de las Leyes" observó que "los diversos caracteres de las naciones son una mezcla de vicios y virtudes, de buenas y malas cualidades. Las mezclas acertadas son aquellas de las cuales resultan grandes beneficios, con frecuencia insospechados" (Montesquieu, 1985:207).

Seguidamente proporciona un ejemplo sumamente ilustrativo: "La buena fe de los españoles ha sido famosa en todos los tiempos. Justino nos habla de su fidelidad para guardar los depósitos: a veces, se han dejado matar por mantenerlos en secreto. La fidelidad que tenían antiguamente la conservan aún hoy. Todas las naciones que comercian en Cádiz confían su fortuna a los españoles y nunca se han arrepentido de ello." (Ibid.)

En la actualidad, el ejemplo más socorrido de cómo la cultura incide en el desarrollo económico, es el del casi milagroso surgimiento de la economía japonesa desde las cenizas de la Segunda Guerra Mundial. Un analista japonés lo consigna: "Otra importante escuela de pensamiento -la culturalconsidera a la economía japonesa como un sistema coherente, congruente con la tradición cultural de ese país. Factores culturales como el énfasis en el grupo pequeño, el intercambio de lealtad del empleado y de paternalismo del patrón, y la intervención del trabajo en lo que a los ojos occidentales parecen ser asuntos personales y privados del trabajador, son las fuerzas motoras del sistema" (Aoki, 1990:10). Este análisis coincide con el de observadores norteamericanos: "Los japoneses ven al individuo como alguien que tiene necesidades económicas, 
sociales, psicológicas y espirituales (...) los directivos japoneses se consideran obligados a cuidar de este aspecto global de la persona, sin fiarlo todo a otras instituciones (como las estatales, las religiosas o la familia)" (Pascale, 1984:118). El vertiginoso crecimiento de la economía japonesa ha sido atribuido, en parte, a esos factores.

\section{Nicaragua: cultura y PYMES}

En esta misma línea, la pregunta que nos hacemos es la siguiente: ¿Existe un contexto cultural apropiado para el salto que deben dar las PYMES en Nicaragua? En la idiosincrasia nicaragüense existen rasgos muy adversos al desarrollo empresarial, y unos pocos favorables que deberían ser aprovechados por las organizaciones que promueven el desarrollo de las PYMES. Aquí abordaremos sólo algunos de ellos.

\section{Concepción del tiempo y desarrollo}

En la base de los rasgos adversos tenemos la concepción del tiempo, reconocida por historiadores de la tecnología como cimiento del desarrollo industrial e imprescindible para sincronizar actividades e incrementar la productividad. Lewis Mumford asegura que "el moderno sistema industrial podría prescindir del carbón, del hierro y del vapor más fácilmente que del reloj" (Mumford, 1971:34).

El reloj empezó normando la vida en los monasterios, pero pronto saltó sus muros y su uso se extendió, trayendo regularidad a la vida de comerciantes y trabajadores. Las campanas del reloj de torre llegaron a regular la vida urbana, dando lugar al recuento y racionamiento del tiempo, creando un mundo de secuencias mensurables y generando el hábito de ahorrar tiempo. La clase burguesa pronto quiso ser regular como un reloj, administrar el tiempo y vivir conforme a la máxima de Benjamín Franklin que postula que "el tiempo es oro".

Nada más lejos de la idiosincrasia nicaragüense que el principio de que el "tiempo es oro". La impuntualidad endémica y epidémica ha echado profundas raíces en nuestro proceder y ha sido objeto de jocosos e iracundos comentarios de nacionales y extranjeros, si bien no es patrimonio exclusivo de los nicaragüenses. Como si esto no fuera suficiente, en la concepción nicaragüense, los tiempos de ocio invaden los tiempos de trabajo. Trabajar y platicar, trabajar y alternar con los amigos (más fácil ahora con el e-mail, que permite darnos barniz de honestos trabajadores frente a la computadora en tanto discurrimos por todos los meandros de la red), o bien trabajar y resolver problemas familiares, son actividades que se trasvasan de manera consuetudinaria. Sin duda, esto nos hace más humanos, pero ha sido blanco de la censura de los aplicados al trabajo: jamás seremos como los alemanes o japoneses. Naturalmente, el problema de la impuntualidad y el trasvase de horarios carcome más a las PYMES que a las grandes empresas.

Mientras las grandes empresas establecen una relación contractual con sus empleados, sobre la base de un documento legal donde los términos de referencia fijan las condiciones de trabajo, 
en la mayor parte de las PYMES tales condiciones permanecen en un estado de vaguedad y no sujetas a lo que prescribe el código del trabajo o reglamentación alguna. Con frecuencia, esta indefinición se pone al servicio de una sobreexplotación. Pero, en cualquier caso, ha servido a un deficiente control de la productividad y pésima sincronización de las interacciones laborales, e incluso de la relación con clientes y proveedores.

La concepción del tiempo tiene una incidencia mayor y más negativa, de cara al desarrollo de las PYMES en el ámbito agropecuario. Los ciclos agrícolas están definidos por las estaciones de invierno y verano. El agro opera bajo la regulación de un reloj estacional y no de un reloj mecánico. Esto imprime un ritmo desmesuradamente lento en los procesos de cambio y adopción de nuevas técnicas, como ya han tenido oportunidad de comprobar los programas de transferencia tecnológica. En ausencia de sistemas de riego artificial, el reloj estacional es determinante.

\section{El providencialismo}

$Y$ ya que tocamos barreras culturales en el agro a la transferencia tecnológica, cabe mencionar una de las más persistentes: el providencialismo. La atribución de los sucesos a causas sobrenaturales está muy difundida y actúa como una barrera para la adquisición de nuevos conocimientos. El providencialismo impide visualizar que el éxito se basa en la aplicación de ciertas técnicas. Eso ocurre, por ejemplo, cuando un campesino adopta prácticas agroecológicas y se pretende que su parcela tenga un efecto vitrina. Aun cuando todos saben que ese agricultor no quema y tiene tierra fértil, los vecinos concluyen:
"A saber; Dios lo ayudó." Y no se vincula la ausencia de determinada plaga o una mejor cosecha a la aplicación de una serie de medidas agroecológicas fácilmente reproducibles.

\section{La picaresca y el oportunismo}

Un elemento que los analistas económicos -particularmente aquellos que profesan la corriente de la "Nueva economía institucional"- han detectado como clave para crear condiciones a los procesos de desarrollo, es la confianza. De acuerdo a sus paladines, existen dos maneras de tratar con el riesgo e incrementar las relaciones mercantiles: la aplicación de sanciones y la confianza. Las sanciones consisten en una serie de incentivos y penalidades cuya aplicación hace poco atractivo el incumplimiento de los acuerdos (Humphrey-Schmitz, 1998). En un programa crediticio de apoyo a las PYMES, un incentivo es la promesa del acceso a montos mayores en caso de pagar. En cambio, una penalización puede estar representada por la amenaza de ejecutar la garantía en caso de pretender evadir sus obligaciones financieras. Obviamente, las sanciones punitivas implican un incremento de los costos de transacción. El embargo supone costos para el beneficiario, independientemente de si llega a convertirse en moroso o no. El embargo requiere de crear unas condiciones que lo hagan eventualmente posible.

La condición fundamental es la constitución de una garantía que tiene costos elevados para el usuario y afecta más a las PYMES, por cuanto los montos solicitados son menores y los costos tienen, por consiguiente, un mayor peso porcentual. 
La confianza es clave para el desarrollo de un capital cultural del que carecemos. Ciertos procesos han ido minando la confianza. La picaresca (con sus ineluctables embaucadores) se ha impuesto y erosiona la confianza que podría ser la base de un arreglo de financiamiento sin intermediarios, con menores costos de transacción y sobre la base de garantías accesibles a los pequeños empresarios. Las relaciones directas cliente-PYME o proveedorPYME podrían conjugar, con menores costos, la búsqueda de empleo rentable que genere ahorros, buscando liquidez para ciertas inversiones. En el caso de la atención financiera a las PYMES, la desconfianza está ligada a la cultura de no pago.

Los códigos financieros fueron distorsionados en la década pasada, de modo que "préstamo" llegó a convertirse en sinónimo de "donativo" o "subsidio". La's condonaciones eran esperadas año con año como agua de mayo, y de hecho caían con mayor puntualidad y más copiosamente. La actitud oportunista no sólo no era institucionalmente censurada y objeto de castigo, sino que fue socialmente fomentada. En la base de esta actitud, a nivel cultural, permanecía una ética del clientelismo con raíces en el binomio mozo-patrón, donde el patrón apadrina al mozo y otorga regalos ocasionales. Esta ética fue reforzada por un clientelismo de carácter político $\mathrm{y}$, en definitiva, se contrapone a una ética de la retribución del esfuerzo. En el caso de la promoción de las PYMES, tanto programas de microfinanzas como de transferencia tecnológica se enfrentan a muchas PYMES que parecen operar bajo el lema: "Sentémonos y esperemos a que la cooperación internacional resuelva nuestros problemas; ellos son los de los billetes"; de modo que en lugar de integrar una iniciativa privada engrosan la horda de los privados de iniciativa y acechan la ocasión de burlar lo convenido con clientes, proveedores y promotores.

A nivel macro, el oportunismo tiene un soporte en el escaso aprecio que hacia los bienes intangibles, como la reputación, experimenta una sociedad consciente de que el robo es el trampolín más frecuentemente utilizado para saltar hacia la riqueza. El botín del Estado y multitud de pequeños botines están consagrados como vías directas hacia la capitalización. Esto genera reacciones en cadena: la corrupción estatal justifica la evasión fiscal, una de las formas de oportunismo más comunes. A su vez, el estado sanciona penalizando a los que no pueden evadir, es decir, elevando las cargas impositivas, especialmente el IGV.

También a nivel macro, la falta de confianza es reforzada por rivalidades nutridas por una atmósfera profundamente politizada, situación que desvía recursos de proyectos productivos y los orienta hacia actividades consideradas de "rentabilidad electoral". Esto vale para el Estado Central, las municipalidades (mejor invertir en un parque, la infraestructura de un centro de salud que en educación, por ejemplo, cosas que se ven a diario y no en producción) y las ONGs.

A nivel de los promotores de PYMES, el famélico estado de la confianza se expresa en la nula concertación o coordinación entre promotores gubernamentales y ONGs, y entre unas y otras 
ONGs. No hay vínculos que articulen sinergias. Pocos acuerdos han tenido duración. Uno de ellos es la Coordinadora Civil, que aglutina a más de 300 ONGs.

\section{Del lado de la demanda, ¿la "maldición de Malinche" o la esquizofrenia promotor-consumi- dor?}

Hasta aquí hemos visto rasgos culturales y la forma en que impactan de manera adversa a las PYMES. Pero nos concentramos en la perspectiva de la oferta. De manera sucinta tocaremos un rasgo que condiciona la demanda de productos de las PYMES. Los programas de apoyo a las PYMES se enfocan generalmente hacia la demanda de cierto sector de bajos ingresos: muebles, calzado, vestuario, con una calidad generalmente baja. No se trata ya del sector de menores ingresos, de hecho convertido en consumidor de los desechos del Primer Mundo: los bultos de ropa y similares, que el profesor Aníbal Ramírez etiquetó como la "economía de la basura". Pero tampoco se trata del sector que más puede ayudar a su desarrollo. Existe otro segmento del mercado, menos explotado por las PYMES y con cuyo comercio se podría mejorar sensiblemente la rentabilidad por unidad de producto: los grupos de clase media, incrementados con las oleadas de nuevos profesionales (tras un mayor acceso a la educación superior) que gozan de un mejoramiento de su nivel de ingresos.

Ambas circunstancias (acceso a mayores niveles educativos y de ingresos) han modificado los patrones de consumo de la clase media. El sociólogo francés Pierre Bourdieu, en una ingeniosa ponencia titulada "La metamorfosis de los gustos", observa que "entre los factores que determinan el cambio dentro de la demanda se encuentra sin lugar a dudas la elevación del nivel, tanto cuantitativo como cualitativo, de la demanda que implica la elevación del nivel de escolaridad (o de la duración de la escolaridad) y que hace que un número cada vez mayor de personas, entre en la competencia por la apropiación de los bienes culturales.

El efecto de la elevación del nivel de escolaridad se ejerce, entre otras formas, por medio de lo que llamo el efecto de asignación estatutaria ('nobleza obliga') que determina a los poseedores de algún título académico, que funciona como título de nobleza, a realizar prácticas como visitar museos, comprar un tocadiscos, leer Le Monde- que se inscriben dentro de su definición social, o quizá podríamos hablar de 'esencia social' " (Bourdieu, 1990:188-189). Ese efecto en Nicaragua ha sido inducido en parte por la proliferación de las maestrías y todo género de post-grados, $y$ se traduce en que los ciudadanos de clase media ya no consuman más que en ciertos ámbitos (los "shopping centers") $\mathrm{y}$ determinada especie de productos.

No obstante, los promotores de PYMES no se percatan de que la clase media ha modificado sus patrones de consumo y constituye un segmento de mercado cuya demanda es más explotable. Su nivel de ingresos ha crecido. Los promotores de PYMES ni siquiera se percatan de que ellos mismos no consumen los productos que promocionan; ni las sillas de Masatepe lucen en sus salas ni el frijol mungo es servido en sus mesas; se van de compras a Metrocentro. 
Una muestra de que no vemos lo que está frente a nuestras narices y del "en casa del herrero cuchillo de palo", que para nuestro contexto podría ser traducido por "en casa del promotor de PYMES, bienes de importación." ¿Se trata de una versión comercial de la maldición de Malinche? "No seás matamama" es una consigna insuficiente cuando las tentaciones del mercado granean. No postulamos que el promotor de PYMES no quiera bienes de calidad. Pero reclamamos que no acuse interés en que sus promovidos sean quienes los produzcan.

Las PYMES en Nicaragua pueden lograr cierto nivel de calidad y acceder a esos mercados "plásticos" y de alta rentabilidad. De acuerdo a ciertos estudios, los trabajadores de las maquilas en Nicaragua presentan la mejor curva de aprendizaje y el más alto nivel de calificación de Centroamérica. No existe una razón técnica que les impida colocar sus productos en los grandes centros comerciales donde se venden camisetas y muñecos Disney hechos en Indonesia, Bangladesh o El Salvador. En otro campo, también los tacos y las pizzas, comidas sencillas, son base de transnacionales de comestibles; hasta las pupusas salvadoreñas ya han ingresado a ese terreno, aunque con dimensiones claramente más modestas. Bienes de manufactura y comida nicaragüense podrían colocarse en segmentos de mercado más remunerativos con una adecuada estrategia y rasgando el velo que propicia la esquizofrenia promotor-consumidor, donde el promotor de PYMES prescinde en sus proyectos de lo que prefiere como consumidor y el consumidor olvida lo que promueve.

\section{Rasgos culturales como recursos de las PYMES}

No todos los rasgos culturales nicaragüenses son adversos al desarrollo de las PYMES. Algo semejante sostenía Montesquieu en materia de legislación cuando escribió: "Si hubiera una nación en el mundo que tuviera humor sociable, corazón abierto, alegría de vivir, gusto, facilidad de comunicar su pensamiento, que fuese vivaz, agradable, a veces imprudente, a menudo indiscreta y que tuviese además valentía, generosidad, franqueza y cierto pundonor, no se deberían poner estorbos a sus hábitos, mediante leyes, para no estorbar a sus virtudes.

Si el carácter es bueno en general, no importa que tenga algunos defectos. (...) Corresponde al legislador acomodarse al espíritu de la nación, siempre que no sea contrario a los principios del Gobierno, pues nada hacemos mejor que aquello que hacemos libremente y dejándonos llevar por nuestro carácter natural" (Montesquieu, 1985:205). Aquí parece estar descrito el carácter del nicaragüense, sin incluir el listado de sus defectos. Postulamos que existen elementos de la idiosincrasia nicaragüense que pueden ser convertidos en recursos. Incluso rasgos aparentemente adversos pueden ser convertidos en oportunidades de desarrollo. En la gestión empresarial, la innovación también consiste en saber detectar y aprovechar oportunidades; en este caso, se trata de convertir rasgos culturales en recursos.

Según el especialista en administración de empresas Peter Drucker, "La innovación es el instrumento específico del empresariado innovador. 
Es la acción de dotar a los recursos de una capacidad nueva de producir riqueza. La innovación crea un 'recurso'. No existe tal cosa hasta que el hombre encuentra la aplicación de algo natural y entonces lo dota de valor económico. Hasta entonces toda planta es un yuyo y todo mineral, una roca. No hace mucho más de un siglo que el petróleo o la bauxita (el óxido de aluminio) fueron considerados recursos. Eran molestias pues ambos hacían infértil el suelo. El hongo de la penicilina era una 'peste' y no un recurso" (Drucker, 1986:45).

\section{La información}

Un género de innovación para los promotores de PYMES podría centrarse sobre los rasgos culturales, dotándolos de utilidad económica. Por ejemplo, en Nicaragua es notoria la fluidez con que discurre la información. En buen nicaragüense decimos que somos "tapudos", pero ese rasgo puede ser una peste que se convierte en recurso. Hasta ahora, el carácter comunicativo del nicaragüense podía ser considerado como un rasgo pintoresco, en ocasiones ameno, en ocasiones imprudente $o$ indiscreto. La innovación de los programas de microfinanzas no convencionales ha hecho de este rasgo un recurso sumamente valioso; empleando promotores locales, acceden a una mina de información clave para unas colocaciones crediticias efectivas. Esto ha permitido que ONGs que canalizan financiamiento de manera no convencional, obtengan información fácilmente acerca de quiénes son los empresarios buenos pagadores y quiénes los morosos, situación que se traduce en una reducción de los costos de transacción, colocaciones efectivas y continuidad del sistema.
En tanto que otras culturas se caracterizan por la reserva y el hermetismo, el nicaragüense, a todos los niveles, descubre incluso lo más vergonzoso. Un literato los describió así: "Otros pueblos -aun en sus capas más bajas- han elaborado multitud de giros para nombrar o para ocultar el nombre de las cosas sucias o consideradas indecentes. Nosotros, por el contrario, inventamos con frecuencia palabras más brutales y símiles más obscenos para recalcar lo que otros esconden" (Cuadra, 1969:48)

El ser "tapudo" siempre ha estado ahí. El mérito es convertir ese rasgo en un recurso económico y sacar ventaja de él. Los programas de microfinanzas necesitan obtener buena información acerca de sus potenciales beneficiarios para evitar riesgos de morosidad en la colocación de recursos. La desconfianza imperante por el oportunismo latente en cada transacción económica, conduce a que los programas tiendan a exigir garantías más sólidas (prendarias, hipotecarias), situación que repercute disparando los costos de transacción. Pero las entidades crediticias dirigidas hacia las PYMES, que han tomado conciencia del valor de la información (los antecedentes crediticios y otros factores) y de que ésta fluye y puede ser captada por los promotores locales, han mejorado sensiblemente su posición hasta un punto que hubiera estado seriamente limitado por un entorno hermético.

Esa estrategia suplió la escasez de confianza, contra desconfianza, "tapudencia". Recolectar y procesar la información se torna un proceso de costos muy bajos; y así se reducen los costos de oportunismo que introducen distorsiones en las relaciones comerciales y financieras. (Humphrey-Schmitz, 98:3334). 
Un ejemplo de la efectividad de este mecanismo, son las reuniones de comités de crédito de las entidades financieras no convencionales, a veces muy cercanas a una tertulia de comadres en el contenido de la discusión, y no en la forma. En una de esta reuniones, uno de los promotores pudo vetar la concesión de un préstamo gracias a que los vecinos de un potencial prestatario le aseguraron que éste era aficionado a apostar en peleas de gallos. El gerente de la entidad financiera estaba dispuesto a concederle el préstamo porque la garantía hipotecaria (de su casa de habitación) presentada permitiría cubrir las obligaciones financieras mediante su ejecución. Entonces el promotor aportó la información concluyente: el solicitante del préstamo estaba tramitando su divorcio y la escritura de la casa estaba a nombre de su esposa. La fluidez de la información fue convertida así en un recurso clave.

Por último, esa fluidez de la información también se ha traducido en que la promoción de los servicios la hagan los clientes. Un servicio eficiente unido al afán comunicativo del nicaragüense, constituye la mejor campaña propagandística.

\section{Cómo convertir en}

\section{recurso un rasgo adverso}

El cruce de tiempos de recreo y trabajo fue mencionado arriba como uno de los rasgos culturales más perniciosos para el desarrollo. Sin que deje de serlo, existen PYMES que han sabido sacar provecho de ello; es decir, han sabido hacer de ese defecto un recurso. En Managua, existía una pequeña fábrica de bloques conocida como "La Bloquera"; hacer bloques no es un negocio muy rentable, pero éste gozaba de una ubicación privilegiada en una de las calles más comerciales de la capital. El dueño, Jairo, que es un hombre emprendedor, observó que sus clientes debían esperar mientras cargaban la mercancía y que, en el ínterin y algo más que el ínterin, consumían lo que ofrecieran las tiendas más cercanas. Entonces Jairo decidió empezar él mismo a vender gaseosas, negocio que pronto transformó en venta de ceviches y cervezas. La mayor parte de sus ingresos no tardaron en provenir de esta segunda empresita. Jairo aprovechó la afición del nicaragüense a tomarse un tiempo de recreo en medio del trabajo y así obtuvo una sinergia entre dos negocios: es preferible comprar bloques donde Jairo por el atractivo de relajarse comiendo ceviche y tomando cervezas. Puede ser que su experiencia no sea representativa de este tipo de negocios, pero muestra cómo un ajuste creativo en la empresa puede transformar un rasgo aparentemente adverso en un recurso.

Desgraciadamente, ese tipo de sinergia tiene olor a herejía, de nuevo en parte por la esquizofrenia del promotor-consumidor.

Los programas de apoyo a las PYMES, con sus líneas monolíticas, no saben hacer de ese rasgo un recurso. Esto ocurre porque no tienen una óptica de empresas, sino de rubros, y promueven una gama muy restringida de rubros. Promueven ciertos productos antes que el desarrollo empresarial. Es más, promueven ciertos productos para ser consumidos solamente de maneras muy restringidas. Una combinación de trabajo y recreo era lograda por las capacitaciones del Programa Campesino a 
Campesino. Se capacitaba a grupos de campesinos y campesinas en el cultivo y la preparación de inusuales clases de leguminosas. Las capacitaciones lograron ser una bien lograda mezcla de aprendizaje y fiesta; pero siempre se tuvo en perspectiva el consumo doméstico, al que difícilmente se podía dar seguimiento. Jamás se montó un comedor donde sirvieran mungo, tortas de soya o canavalia, pozol de gandul, etc. Se promovió que el campesino los cultivara, pero no una comidería que promocionara esa dieta. Y ese hubiera sido el mejor dispositivo de promoción continua y sinergia entre cultivo y consumo, más allá de la capacitación puntual. Tampoco se pensó que lo que no era atractivo como producto a ser vendido por una PYME, no podía ser atractivo en el consumo doméstico, y que la introducción de nuevos productos a la dieta del nicaragüense pasaba por un cambio cultural- de los patrones de consumo.

\section{La mano-vuelta}

La desconfianza ha sido presentada como uno de los mayores impedimentos para el desarrollo de las PYMES. La gran empresa monta sus relaciones comerciales sobre rieles legales y accede a un mayor nivel de formalización; en tanto las PYMES son más dependientes de vínculos informales, convenios "de palabra", acuerdos tácitos basados en códigos sociales actualmente muy debilitados por la politización del entorno, la corrupción a todos los niveles, la picaresca y el oportunismo. "No poner todos los huevos en la misma canasta", es decir, diversificar, es el seguro de muchas PYMES porque "el que se quemó con leche, hasta las cuajadas sopla." Pero no basta.
En realidad, existen mecanismos poco explotados por los promotores de PYMES, de hecho consagrados por la tradición cultural y que en cambio, no pueden ser empleados por las grandes empresas. Se menciona el fracaso de las cooperativas como una muestra de lo poco "cooperativo" que es el nicaragüense, pero hay formas de cooperación campesina a las que se les presta escasa atención. Tomemos, como ejemplo, el principio de "mano vuelta", que ha interpuesto sus buenos oficios en tantas transacciones.

La "mano vuelta" es un intercambio de servicios; el campesino que carece de capital para pagar ayudantes, pero que en ciertos períodos pico de trabajo requiere mano de obra adicional, puede contratar la ayuda de un vecino bajo la promesa de corresponderle de la misma manera cuando éste lo solicite. La "mano vuelta" es un trueque de servicios realizados en distintos momentos. Eso permite incluso tener sus "ahorros" y "crédito" de días de trabajo. Pero esa transacción sólo se realiza con gente de confianza: vecinos, compadres, amigos cercanos. Lo que importa aquí es el substrato cultural que hace posible este intercambio.

Algunas instituciones que promueven PYMES han sabido pulsar esa tecla cultural. Esto lo han conseguido, por ejemplo, algunas instituciones crediticias donde los beneficiarios se han "apropiado" de la institución, es decir, ha sido construida una relación amistosa usuario-prestatario de los servicios. Se trata de lograr que la gente perciba que la institución es su "brother". La llamada "cultura de no pago", que consiste en una plausibilidad social del incumplimiento de las obligaciones financieras, puede ser superada por un tácito pacto 
de caballeros estilo "mano vuelta". El usuario concluye que "hay que pagarle a la institución porque la institución nos ayuda". La apropiación hace que -por la participación de promotores locales- la institución crediticia incurra en menores costos y tenga buenas recuperaciones.

Ese principio (de hecho una sanción) supera la desconfianza, porque cualquier intento de oportunismo expone a pérdidas que serían superiores a las ventajas derivadas del incumplimiento (Ibid:35), a saber: la ruptura de este género de relaciones y futura inaccesibilidad a los servicios, sean financieros o laborales, sea entre campesinos o entre éstos y ONGs. La sostenibilidad de las relaciones que benefician a ambas partes es del interés de ambas partes. La sostenibilidad de la relación de negocios en sí misma es el mejor colateral del crédito (Ibid:36).

Incluso instituciones públicas han sabido recurrir a la "mano vuelta". La Alcaldía de San Francisco Libre es un ejemplo en este campo. Generalmente los campesinos suelen evadir sus obligaciones tributarias para con la municipalidad.

En parte porque la Alcaldía carece de mecanismos eficaces de registro de propiedades y de cobro, y en parte, porque muchos de ellos no tienen con qué pagar, especialmente si el cobro les llega en bloque al final del año. Por su parte, a las municipalidades les urge contar con esos fondos para proveer los servicios que son de su competencia: limpieza de calles, mantenimiento y construcción de caminos, parques y andenes, etc. La Alcaldía de San Francisco Libre aplicó la "mano vuelta" aceptando, como pago de los impuestos $\mathrm{y}$ en lugar de dinero en efectivo, la prestación de los servicios mencionados por parte de los contribuyentes.

Algo semejante se podría hacer de modo que saquen provecho las PYMES. Montar PYMES prestadoras de servicios públicos contratadas por las alcaldías tras licitación, sería una forma de combinar promoción de PYMES y descentralización a nivel local. Aunque la ejecución de esta propuesta tendrá que enfrentar el gran obstáculo de la politización y el nepotismo que concentran la ejecución de los servicios municipales en administradores ineficientes, la propuesta en sí tiene mucho atractivo. No necesariamente estaríamos hablando de privatizar, sino incluso de empezar a prestar servicios hasta ahora inexistentes y necesarios para el desarrollo del municipio. De hecho muchas municipalidades no prestan siquiera un servicio tan básico y de bajo costo como es el de recolección de basura.

Existen muchas oportunidades económicas esperando, mientras algunos siguen preguntándose si nuestros rasgos culturales terminarán potenciando $o$ estancando el desarrollo de las PYMES. La respuesta a esa interrogante dependerá del empeño que pongan los promotores de PYMES, de su permanencia en el terreno para captar los rasgos culturales y de que sepan diseñar acciones que los conviertan en recursos. Los rasgos culturales no son improductivos, productivos o antiproductivos en sí mismos; están esperando a que innovaciones empresariales organizativas, publicitarias, descubridoras de resortes en la demanda, etc., los doten de un carácter productivo y los conviertan en recursos. 


\section{Bibliografía}

- AOKI, M. (1990). La estructura de la economía japonesa. México. Fondo de Cultura Económica.

- BOURDIEU, P. (1990). Sociología y cultura. México, Editorial Grijalbo.

- CUADRA, P. A. (1969). El Nicaragüense. Madrid, Ediciones Cultura Hispánica.

- DRUCKER, P. F. (1986). La innovación y el empresario innovador. La práctica y los principios. Buenos Aires, Editorial Sudamericana.

- GEYER, K.; GONZÁLEZ, P.; QUECK, S. y SCHOR, G. (1997). La industria del financiamiento a la micro y pequeña empresa en Nicaragua. Análisis de oferentes seleccionados (Borrador). Frankfurt, Internationale Projekt Consult Gmbh (IPC).

- HUMPHREY, J. y SCHMITZ, H. (1998). "Trust and Inter-Firm Relations in Developing and Transition Economies", en The Journal of Development Studies, Vol.34, No.4.

- LA PRENSA, 19 de noviembre de 1997. Managua.

- MONTESQUIEU, (1985). Del Espíritu de las Leyes. Madrid, Editorial Tecnos.

- MUMFORD, L. (1971). Técnica y civilización. Madrid, Alianza Editorial.

- NORTH, D. C. (1993). Instituciones, cambio institucional y desempeño económico. México. Fondo de Cultura Económico.

- PASCALE, R. T. y ATHOS, A. G. (1984). El secreto de la técnica empresarial japonesa. México, Editorial Grijalbo.

- SABA, A. (1997). El modelo italiano: la especialización flexible y los distritos industriales. Argentina. Editorial de la Universidad Nacional de la Plata.

- SAENZ, A. (1996). "Formas jurídicas, legalización e inscripción de las PYMES en Nicaragua", en

Materiales de Estudio y Trabajo, $\mathrm{N}^{\circ} 20$. Managua. Instituto de Investigaciones y Consultorías Económicas y Sociales (ICES), Fundación Friedrich Ebert,

- WEBER, M. (1975). La ética protestante y el espiritu del capitalismo. Barcelona, Ediciones Península.

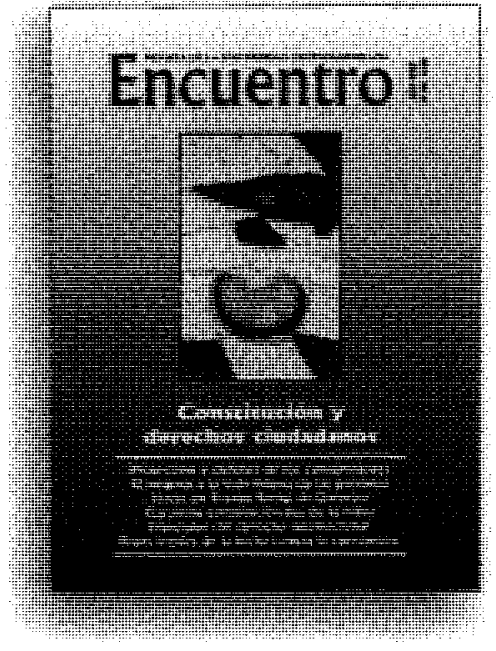

Solicitar información a:

Revista Encuentro

Tel.: (505) 2783923 al 3927

Fax.: (505) 2670106.

E-mail: encuentr@ns.uca.edu.ni

Apdo. Postal \#69

Managua, Nicaragua.

\section{Revista Encuentro Una publicación de la Universidad Centroamericana (UCA)}

ANÚNCIESE

\ SUSCRÍbAsE

SLLICITE CANJE

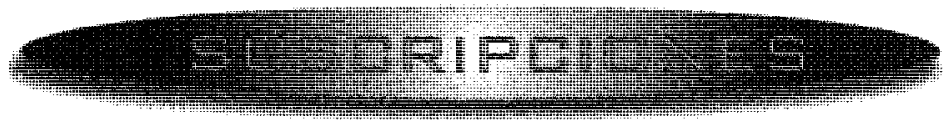

Nicaragua $C \$ 120.00$ / Centroamérica USD $\$ 20.00$ Resto de América Latina USD\$30.00 / EEUU, Canadá y Europa USD $\$ 35.00$ / Asia, Africa y Oceanía USD $\$ 40.00$ Elaborar los cheques a nombre de Universidad Centroamericana. Los cheques del extranjero deben ser negociables en bancos de EEUU. 